\title{
Host rock controls on hydrothermal geochemistry
}

\author{
ALYSIA COX ${ }^{12^{*}}$ AND BRIAN E. ST. CLAIR ${ }^{12^{*}}$
}

"Montana Technological University, Butte, MT, USA 59701, acox@mtech.edu,bstclair@mtech.edu

'Yachay Tech, Urcuqui, Imbabura, Ecuador

Microbial habitability is driven by aqueous geochemistry which is controlled by host rock composition and influenced by other processes such as extent of water-rock reaction. Igneous rock compositions hosting hot springs on Earth vary by tectonic setting and from mafic to felsic including divergent basaltic with a hot spot (Iceland), subduction zone andesitic (Ecuadorian Andes), and continental rhyolitic hot spot (Yellowstone). Aqueous geochemical comparisons between hot springs hosted in a subduction zone vs. continental hot spot reveal higher $\mathrm{Ca}^{2+}, \mathrm{Mg}^{2+}$, and $\mathrm{Fe}^{2+}$ (for a given $\mathrm{pH}$ ) and lower $\mathrm{Al}_{\mathrm{t}}$ in the andesite as predicted based on rock composition, but variable $\mathrm{Na}^{+}$, suggesting seawater entrainment or another process. As is consistently elevated in the andesite hosted hot springs. Whereas the Yellowstone system has more total hydrothermal features $(>10,0000)$, samples (i $\sim 75$ ), and geochemical variability, samples from every known hydrothermal feature with a temperature greater than $50^{\circ} \mathrm{C}(\mathrm{i} \approx 52)$ in the Ecuadorian upper volcanic belt of the Andes yielded a remarkably consist aqueous composition dictated by the host rock. These varations create environments with different chemical potentials allowing for diverse microbial metabolisms.

Phase separation creates hot springs with divergent $\mathrm{pH}$ values, and sulfate and chloride concentrations in both the subduction zone and continental hot spot springs, providing distinct habitats for microbes. The dominant $\mathrm{pH}$ value in the Ecuadorian Andes hot springs is 6.2, ranging from 6 to 6.5, with one notable system featuring phase separation producing a $\mathrm{pH}$ value of 4.4. The dominant $\mathrm{pH}$ of 6.2 results from carbonate system buffering and $\mathrm{CO}_{2}$ saturated fluids partially reacted with andesitic rock. In contrast, Yellowtone hot spring $\mathrm{pH}$ values range from less than 2 to 9 . The nearly bimodal $\mathrm{pH}$ distribution of high temperature samples is a result of complex hydrology resulting in fluid separation and mixing with shallow groundwater thereby producing low $\mathrm{pH}$ values through oxidation of hydrogen sulfide to sulfuric acid, whereas the more pristine hydrothermal fluids are alkaline chloride rising from depth.

Together, the varying host rock compositions of these hydrothermal systems producing corresponding aqueous geochemistry provide a foundation for predicting microbial metabolisms and habitability on Earth and elsewhere. 